\title{
Low Seroprevalence of SARS-CoV-2 in Rhode Island blood donors during may 2020 as determined using multiple serological assay formats
}

Daniel J. Nesbitt ${ }^{1 \dagger}$, Daniel P. Jin ${ }^{1 \dagger}$, Joseph W. Hogan², Jenny Yang ${ }^{1}$, Haidee Chen ${ }^{1}$, Philip A. Chan ${ }^{3}$, Melissa J. Simon ${ }^{4}$, Matthew Vargas ${ }^{4}$, Ewa King ${ }^{3,5}$, Richard C. Huard ${ }^{3,5}$, Utpala Bandy ${ }^{3}$, Christopher D. Hillyer ${ }^{1}$ and Larry L. Luchsinger ${ }^{1 *}$ (D)

\begin{abstract}
Background: Epidemic projections and public health policies addressing Coronavirus disease (COVID)-19 have been implemented without data reporting on the seroconversion of the population since scalable antibody testing has only recently become available.

Methods: We measured the percentage of severe acute respiratory syndrome- Coronavirus-2 (SARS-CoV-2) seropositive individuals from 2008 blood donors drawn in the state of Rhode Island (RI). We utilized multiple antibody testing platforms, including lateral flow immunoassays (LFAs), enzyme-linked immunosorbent assays (ELISAs) and high throughput serological assays (HTSAs). To estimate seroprevalence, we utilized the Bayesian statistical method to adjust for sensitivity and specificity of the commercial tests used.
\end{abstract}

Results: We report than an estimated seropositive rate of RI blood donors of approximately $0.6 \%$ existed in AprilMay of 2020. Daily new case rates peaked in RI in late April 2020. We found HTSAs and LFAs were positively correlated with ELISA assays to detect antibodies specific to SARS-CoV-2 in blood donors.

Conclusions: These data imply that seroconversion, and thus infection, is likely not widespread within this population. We conclude that lgG LFAs and HTSAs are suitable to conduct seroprevalence assays in random populations. More studies will be needed using validated serological tests to improve the precision and report the kinetic progression of seroprevalence estimates.

Keywords: COVID-19, SARS-CoV-2, Seroprevalence, Rhode Island, Pandemic, Serology, Antibody

\footnotetext{
* Correspondence: lluchsinger@nybc.org

${ }^{\dagger}$ Daniel J. Nesbitt and Daniel P. Jin contributed equally to this work.

${ }^{1}$ New York Blood Center, Lindsley F. Kimball Research Institute, New York, NY, USA

Full list of author information is available at the end of the article
}

(C) The Author(s). 2021 Open Access This article is licensed under a Creative Commons Attribution 4.0 International License, which permits use, sharing, adaptation, distribution and reproduction in any medium or format, as long as you give appropriate credit to the original author(s) and the source, provide a link to the Creative Commons licence, and indicate if changes were made. The images or other third party material in this article are included in the article's Creative Commons licence, unless indicated otherwise in a credit line to the material. If material is not included in the article's Creative Commons licence and your intended use is not permitted by statutory regulation or exceeds the permitted use, you will need to obtain permission directly from the copyright holder. To view a copy of this licence, visit http://creativecommons.org/licenses/by/4.0/ The Creative Commons Public Domain Dedication waiver (http://creativecommons.org/publicdomain/zero/1.0/) applies to the data made available in this article, unless otherwise stated in a credit line to the data. 


\section{Background}

The Severe Acute Respiratory Syndrome Coronavirus (SARS-CoV)-2 pandemic is ongoing, with more than 30 million cases and over 550,000 deaths reported from Coronavirus disease (COVID)-19 in the United States as of early April, 2021 [1, 2]. Transmission models of SARS-CoV-2, based on numerous inferences of other immune responses to viral infections, suggest that infection may provide some immunity to reinfection $[1,3]$. If true, the utility of serological tests to identify those who have acquired antibodies against SARS-CoV-2 (seroconversion) and the frequency of seroconversion in the population (seroprevalence) is a powerful tool with which to guide public health policies $[4,5]$. It is critical to determine how many individuals have had COVID-19 and are thus likely to be immune, and differentiate them from those who have not been infected. These data are necessary to inform modeling projections and policy making that will allow an optimal approach to "reopening" a country, state, or region, and furthermore, these data must be accurate and reliable.

Serological assays rely on accurate recognition and ideally quantification of antibodies that recognize viral antigens specific to SARS-CoV-2. Optimal test characteristics include high levels of sensitivity and specificity. Coronaviruses have four major structural proteins; spike (S) protein (containing the S1 domain and RBD motif), nucleocapsid $(\mathrm{N})$ protein, membrane $(\mathrm{M})$ protein, and envelop (E) protein [6]. Research conducted on 2005 SARS-CoV-1 and Middle East respiratory syndrome Coronavirus (MERS-CoV), which are highly related to SARS-CoV-2, found that recovered individuals produced the strongest immunogenic antibodies against antigens of the S- and N-proteins [7]. Thus, the development of serological tests for SARS-CoV-2 antibodies has focused heavily on the detection of antibodies against these viral proteins. Antibody-based tests vary in both technology (platform) and target antigen (design). In May of 2020, the FDA announced a reversal in its emergency use authorization (EUA) and approval policies in order to help ensure that reliable tests are used to accurately measure seroconversion in a population. Some tests have received EUA but limited data is available. Considerable variability in test characteristics, particularly sensitivity, implies that there may not yet be an ideal test design and instrument platform. This also can lead to variability and potential bias in the estimation of the level of immunity in various locales or subpopulations [8, 9].

Multiple serological assays have been developed to detect SARS-CoV-2 antibodies from whole blood, plasma and serum. Essentially, three platforms of serological testing have been adopted: 1) enzyme linked immunosorbent assays (ELISA), 2) high-throughput serological assays (HTSA) and 3) lateral flow assays (LFA). ELISAs offer wide flexibility for research laboratories to select virtually any antigenic protein of interest and assay patient sera to provide highly sensitive, quantitative results. HTSAs are more suitable to clinical laboratories processing large volumes of samples. Although HTSAs offer a narrower selection of antigen choices, these platforms offer high-throughput capacity, high sensitivity and can be integrated into clinical lab testing facilities. LFAs also offer limited antigen diversity, but function with small volumes of whole blood, plasma or sera (1 drop, 20uL) and require short test development times ( $\leq 30 \mathrm{~min})$ allowing administration and test results at the point of care. As reagent supply, testing capacity and affordability vary across the country, the clinical community will undoubtedly resort to using multiple platforms to fill the demand.

Underreporting of COVID-19 cases may be occurring, which could inaccurately reflect the morbidity and mortality of SARS-CoV-2 [10]. The objective of this study was to assess the seroprevalence in a sample of blood donors in Rhode Island using commercially available serology tests [11]. To this end, consecutive blood donors were enrolled though the Rhode Island Blood Center (RIBC) into a pilot study with the goal of estimating seroprevalence for the population represented by those who donate blood on a regular basis. This pilot is part of a larger statewide effort to estimate seroprevalence, including a statewide community survey and testing on specific populations of interest.

\section{Methods}

\section{Whole blood donors and sample preparation}

From April 27, 2020 - May 11, 2020, consecutive Rhode Island Blood Center $(\mathrm{RIBC})$ donors $(n=2008)$ received a 2-question survey and completed a blood or plasma donation. Donor blood samples were then tested using two commercially available serology tests and an in-house ELISA, described below. Plasma or serum was isolated from whole blood samples collected in silica clot activator tubes. Samples were extracted, aliquoted to minimize future freeze-thaw cycles, and stored at $-80^{\circ} \mathrm{C}$. Choropleth was generated in house from donor zip code prefix data using the web tool, http://www.heatmapper.ca/ geocoordinate/ [12].

\section{Lateral flow ImmunoAssay (LFA)}

LFAs were conducted using the Standard Q COVID-19 IgM/IgG Duo rapid immunochromatography test kit (SD Biosensor; South Korea) [13]. The kit contained two individual assay cartridges each with a detection band for IgG and IgM against SARS-CoV2 specific epitopes as well as an internal positive control. For each assay, $10 \mu \mathrm{L}$ donor serum was applied to the sample pad, followed by two drops of proprietary running buffer according to the 
manufacturer's instructions. After $15 \mathrm{~min}$, a visual eye determination was made, and high-resolution images of the detection zone were taken and saved as. JPEG files. All tests were performed at room temperature.

\section{High-throughput serology assays}

Serum samples were barcoded and dispatched to RIBC. Samples were analyzed using the VITROS Immunodiagnostic Products Anti-SARS-CoV-2 Total Ig Test with the VITROS 5600 (Ortho Clinical Diagnostics; USA). All assays were performed by trained RIBC employees according to the manufacturer's standard procedures.

\section{In-house SARS-Cov2 binding-antibody ELISAs}

Flat-well, nickel-coated 96 well ELISA plates (Thermo Scientific; USA) were coated with $2 \mu \mathrm{g} / \mathrm{mL}$ of recombinant S1 spike protein, nucleocapsid protein, or Receptor Binding Domain (RBD) spike protein specific to SARSCoV-2 in resuspension buffer (1\% Human Serum Albumin in $0.01 \% \mathrm{PBST}$ ) and incubated in a stationary humidified chamber overnight at $4{ }^{\circ} \mathrm{C}$. On the day of the assay, plates were blocked for $30 \mathrm{~min}$ with ELISA blocking buffer (3\% W/V non-fat milk in PBST). Standard curves for both $\mathrm{S} 1$ and RBD assays were generated by using mouse anti-SARS-CoV spike protein monoclonal antibody (clone [3A2], ABIN2452119, Antibodies-Online) as the standard. Anti-SARS-CoV-2 Nucleocapsid mouse monoclonal antibody (clone [7E1B], bsm-41,414 M, Bioss Antibodies) was used as a standard for nucleocapsid binding assays. Monoclonal antibody standard curves and serial dilutions of donor sera were prepared in assay buffer ( $1 \%$ non-fat milk in PBST) and added to blocked plates in technical duplicate for $1 \mathrm{~h}$ with orbital shaking at room temperature. Plates were then washed three times with PBST and incubated for $1 \mathrm{~h}$ with ELISA assay buffer containing Goat antiHuman IgA, IgG, IgM (Heavy \& Light Chain) Antibody-HRP (Cat. No. ABIN100792, AntibodiesOnline) and Goat anti-Mouse IgG2b (Heavy Chain) Antibody-HRP (Cat. No. ABIN376251, AntibodiesOnline) at 1:30000 and 1:3000 dilutions, respectively. Plates were then washed three times, developed with Pierce TMB substrate for $5 \mathrm{~min}$, and quenched with $3 \mathrm{M} \mathrm{HCl}$. Absorbance readings were collected at 450 nm. Standard curves were constructed in Prism 8.4 (Graphpad Software Inc.) using a Sigmoidal 4PL NonLinear Regression (curve fit) model.

\section{Estimated Seroprevalence statistical calculations}

For each assay, seroprevalence was estimated using a Bayesian statistical method that adjusts for sensitivity and specificity of the specific test. The operating characteristics for the Ortho assay were obtained from the technical report distributed by the manufacturer; for SD Biosensor we relied on local validation data.

\section{Results}

A total of 2008 donor samples were collected for this study between April and May of 2020, just as the daily new case rates peaked in RI (https://ri-department-ofhealth-covid-19-data-rihealth.hub.arcgis.com/). We compared age, sex and race/ethnicity of the sample group to values reported for Rhode Island from the 2010 U.S. Census. The median age of donors was 56 years, significantly older than the Rhode Island median age of 39.4 years (Fig. 1A, Table 1). The sample had $\sim 47 \%$ female donors compared to $52 \%$ statewide (Fig. 1B, Table 1). The distribution of donor Race/ethnicity was $84.7 \%$ white, $2.7 \%$ Hispanic/Latino and $0.50 \%$ Black/African American, compared to the state distribution of $81 \%$ white, $12.4 \%$ Hispanic/Latino and 5.7\% Black/African American. A full comparison appears in Table 1 and Fig. 1. Notably, $9.3 \%$ of donors responded to ethnicity as 'Declined' or 'Not Specified'. Finally, geographic location of donors associated with population density, such as Providence and Warwick, with lower representation in the western and coastal regions of Rhode Island (Fig. 1C, D). Thirteen donors were identified as convalescent plasma or whole blood donors that were aware of their seroconversion status prior to enrollment in the study and were removed from the analysis, which adjusted the total donors analyzed to 1996.

To quantify seroprevalence in this sample, donor samples were tested with an HTSA platform (Ortho Clinical Diagnostics VITROS Total Ig Test) and an LFA platform (SD Biosensor IgM/IgG test). The IgM-only LFA assay yielded 68 positive tests for a $2.7 \%$ (95\% CI 1.7 to $3.8 \%$ ) seroconversion (Fig. 2A, Table 2). In contrast, the IgGonly LFA assay yielded 13 positive tests for $0.6 \%$ seroconversion (95\% CI 0.3 to $1.1 \%$ ) and was in agreement with the Ortho HTSA assay, which had 14 positives for a $0.6 \%$ seropositivity (95\% CI 0.2 to 1.1) (Fig. 2A, Table 2).

In total, $3.9 \%$ of all samples (77 seropositive donors) were reactive for at least one test. To report overlap between test results, we constructed a Venn diagram (Fig. 2B, Table 2). Notably, $\sim 76 \%$ of seropositive samples (59 of 77 ) were reactive only with the IgM-only LFA test. The remaining $0.9 \%$ of all samples (18 seropositive donors) showed a $~ 62 \%$ overlap between Ortho and IgG LFA assays (10 of 18 seropositive donors). Samples that showed at least 2 or more positive reactions was $0.55 \%$ (11 seropositive donors).

Donors completed a two-part questionnaire as to whether they had COVID-19 and the results of the diagnostic PCR test. However, error could be associated with this assessment due to inaccuracy of self-reported infection status as a result of false positive/negative test 


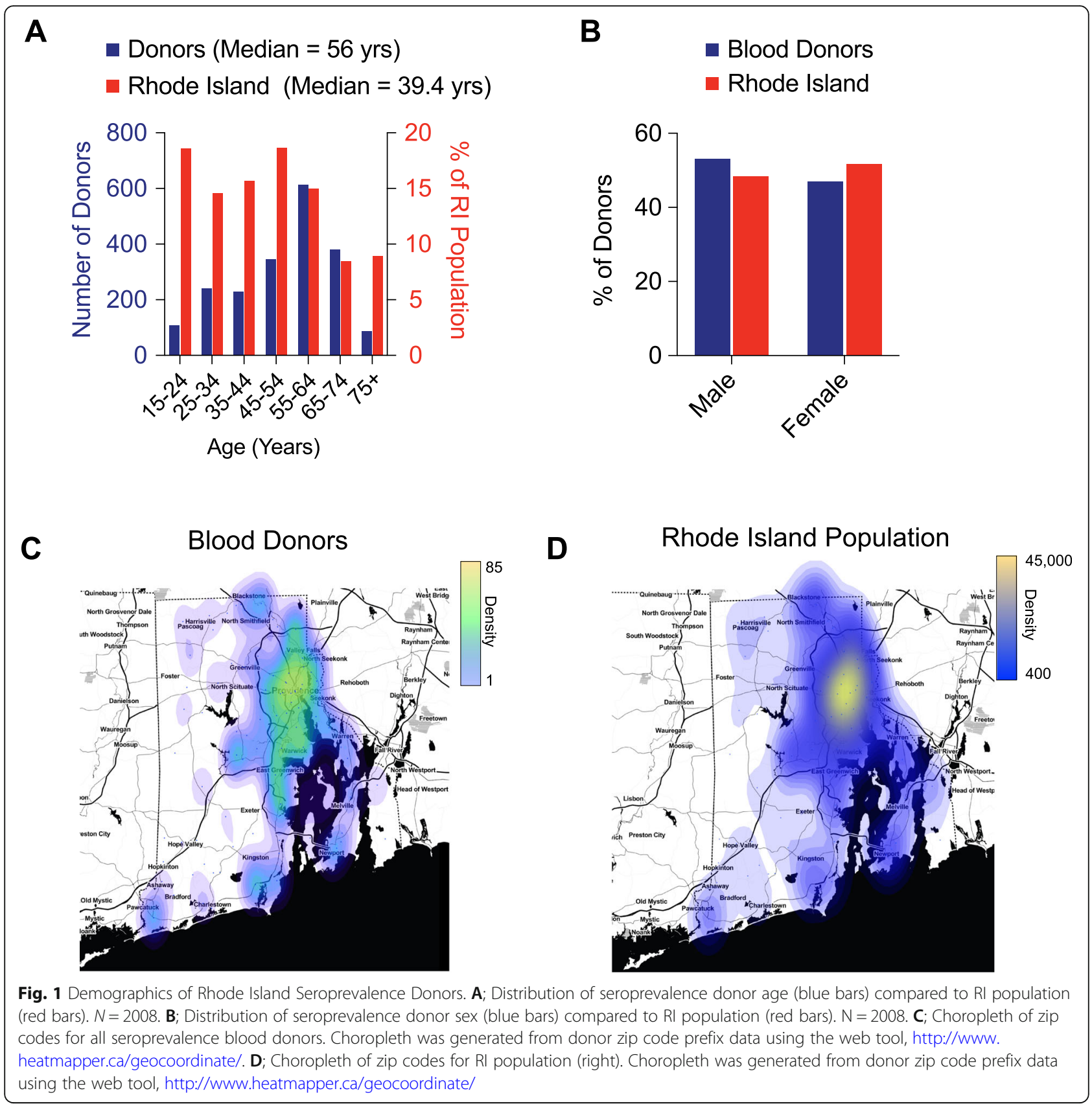

results or inaccurate donor reporting. Overall, 76 donors responded that they had received a diagnostic PCR test for COVID-19; of these, 13 donors tested positive while 63 tested negative (Table 3). Of those reporting positive PCR, 4/13 (44\%) had positive IgM LFA, 9/13 (69\%) had positive IgG, and 11/13 (85\%) had positive Ortho test. Of those reporting negative PCR, 59/63 (94\%) tested IgM negative, 61/63 (97\%) tested IgG negative, and the same number (97\%) tested Ortho negative. These limited data are in line with manufacturer-reported estimates of sensitivity and specificity. Importantly, the reliance on self-reported data must be interpreted with caution, and there was no ability to account for the time since infection, which could impact the sensitivity calculations.

The gold-standard in antibody quantification is the ELISA assay for its flexibility in antigen diversity and quantification methodology using monoclonal antibodies to generate standard curves. We designed in-house ELISA assays against S1 and NP specific to SARS-CoV-2 antibodies, since these antigens have been described to elicit the most immunogenic response to infection based on SARS-CoV and MERS research. We analyzed all 77 samples that were positive for any serological assay and 30 random samples that were negative for all serological 
Table 1 Distribution of Study Donor Age, Sex and Ethnicity compared to 2010 Rhode Island Population

\begin{tabular}{|c|c|c|c|c|}
\hline Age Range & Study Donors & \% Study Donors & RI Population & \% RI Population \\
\hline $15-24$ & 108 & $5.38 \%$ & 162,213 & $18.63 \%$ \\
\hline $25-34$ & 241 & $12.00 \%$ & 126,962 & $14.58 \%$ \\
\hline $35-44$ & 230 & $11.45 \%$ & 136,860 & $15.72 \%$ \\
\hline $45-54$ & 347 & $17.28 \%$ & 162,350 & $18.64 \%$ \\
\hline $55-64$ & 614 & $30.58 \%$ & 130,589 & $15.00 \%$ \\
\hline $65-74$ & 381 & $18.97 \%$ & 73,879 & $8.48 \%$ \\
\hline $75+$ & 87 & $4.33 \%$ & 78,002 & $8.96 \%$ \\
\hline Total & 2008 & & 870,855 & \\
\hline \multicolumn{5}{|c|}{ Source: http://www.dltri.gov/lmi/census/demo/agesex.htm } \\
\hline Gender & Study Donors & \% Study Donors & RI Population & \% RI Population \\
\hline Male & 1064 & $53.01 \%$ & 508,400 & $48.30 \%$ \\
\hline Female & 944 & $46.99 \%$ & 544,167 & $51.69 \%$ \\
\hline Total & 2008 & & $1,052,567$ & \\
\hline \multicolumn{5}{|c|}{ Source: http://www.dlt.ri.gov/lmi/census/demo/agesex.htm } \\
\hline Ethnicity & Study Donors & $\%$ Study Donors & RI Population & \% RI Population \\
\hline White & 1700 & $84.66 \%$ & 856,869 & $81.41 \%$ \\
\hline Black or African American & 10 & $0.50 \%$ & 601,89 & $5.72 \%$ \\
\hline American Indian \& AK Native & 5 & $0.25 \%$ & 6058 & $0.58 \%$ \\
\hline Asian & 5 & $0.25 \%$ & 30,457 & $2.89 \%$ \\
\hline Hawaiian/Pacific Islander & 0 & $0.00 \%$ & 554 & $0.05 \%$ \\
\hline Hispanic/Latino or Other Race, Alone & 59 & $2.94 \%$ & 63,653 & $6.05 \%$ \\
\hline Two or More Races & 20 & $1.00 \%$ & 34,787 & $3.30 \%$ \\
\hline Decline & 23 & $1.154 \%$ & 0 & $0.00 \%$ \\
\hline Not Specified & 186 & $9.26 \%$ & 0 & $0.00 \%$ \\
\hline Total & 2008 & & 870,855 & \\
\hline
\end{tabular}

assays as controls for S1 and NP antibodies. Surprisingly, S1 antibody quantification showed a median value of $73.8 \mu \mathrm{g} / \mathrm{mL}$ for seropositive samples compared to $45.8 \mu \mathrm{g} / \mathrm{mL}$ for seronegative controls (Fig. 2C) indicating moderate antibodies against S1 epitopes. Similarly, NP antibody quantification showed a median value of 46.6 $\mathrm{ng} / \mathrm{mL}$ for seropositive samples compared to $31.9 \mathrm{ng} / \mathrm{mL}$ for seronegative controls, also indicating moderate antibodies against NP epitopes. However, there was $\geq 100$ fold range of antibody values for seropositive samples in each ELISA test, suggesting that some of the seropositive samples, but not all, were significantly reactive in $\mathrm{S} 1$ and NP ELISA, which is highly predictive of neutralizing activity. Spearman's correlation analysis of all five tests showed a high degree of positive association between ELISA, HTSAs and IgG LFA tests while IgM LFA test was negatively correlated (Fig. 2D). Thus, we hypothesized that samples reactive for either the IgG LFA and/ or the Ortho HTSA may have higher ELISAs values than samples that were reactive only for IgM LFA test.
To investigate this, we evaluated seropositive donors that were reactive to either the Ortho HTSA assay (Ortho $\left.{ }^{+}\right)$, the IgG LFA $\left(\operatorname{IgG}^{+}\right)$or only the IgM LFA $\left(\operatorname{IgM}^{+}\right.$ only). As expected, the median Ortho HTSA value was $10^{4}$ higher for both the Ortho ${ }^{+}$and $\mathrm{IgG}^{+}$groups compared to the $\operatorname{IgM}^{+}$-only group (158.5 and $114.8 \mathrm{AU}$ vs 0.02 AU, respectively) (Fig. 2E). Similarly, both S1 and NP ELISAs showed significantly higher median antibody concentrations for the Ortho ${ }^{+}$and $\mathrm{IgG}^{+}$groups than for the $\mathrm{IgM}^{+}$-only group $(\mathrm{S} 1 ; 467.2 \mu \mathrm{g} / \mathrm{mL}$ and $363.9 \mu \mathrm{g} / \mathrm{mL}$ versus $60.5 \mu \mathrm{g} / \mathrm{mL}$ and $\mathrm{NP} ; 320.4 \mathrm{ng} / \mathrm{mL}$ and $204.8 \mathrm{ng} /$ $\mathrm{mL}$ versus $39.4 \mathrm{ng} / \mathrm{mL}$ ) (Fig. $2 \mathrm{~F}, \mathrm{G}$ ). Importantly, these results conclude that IgG LFA and Ortho HTSA assays, but not the IgM LFA assay, correlate with immunogenic antibodies specific to SARS-CoV-2 as detected by ELISA.

\section{Discussion}

This is among the first studies to evaluate statewide seroprevalence using blood donations. COVID-19 


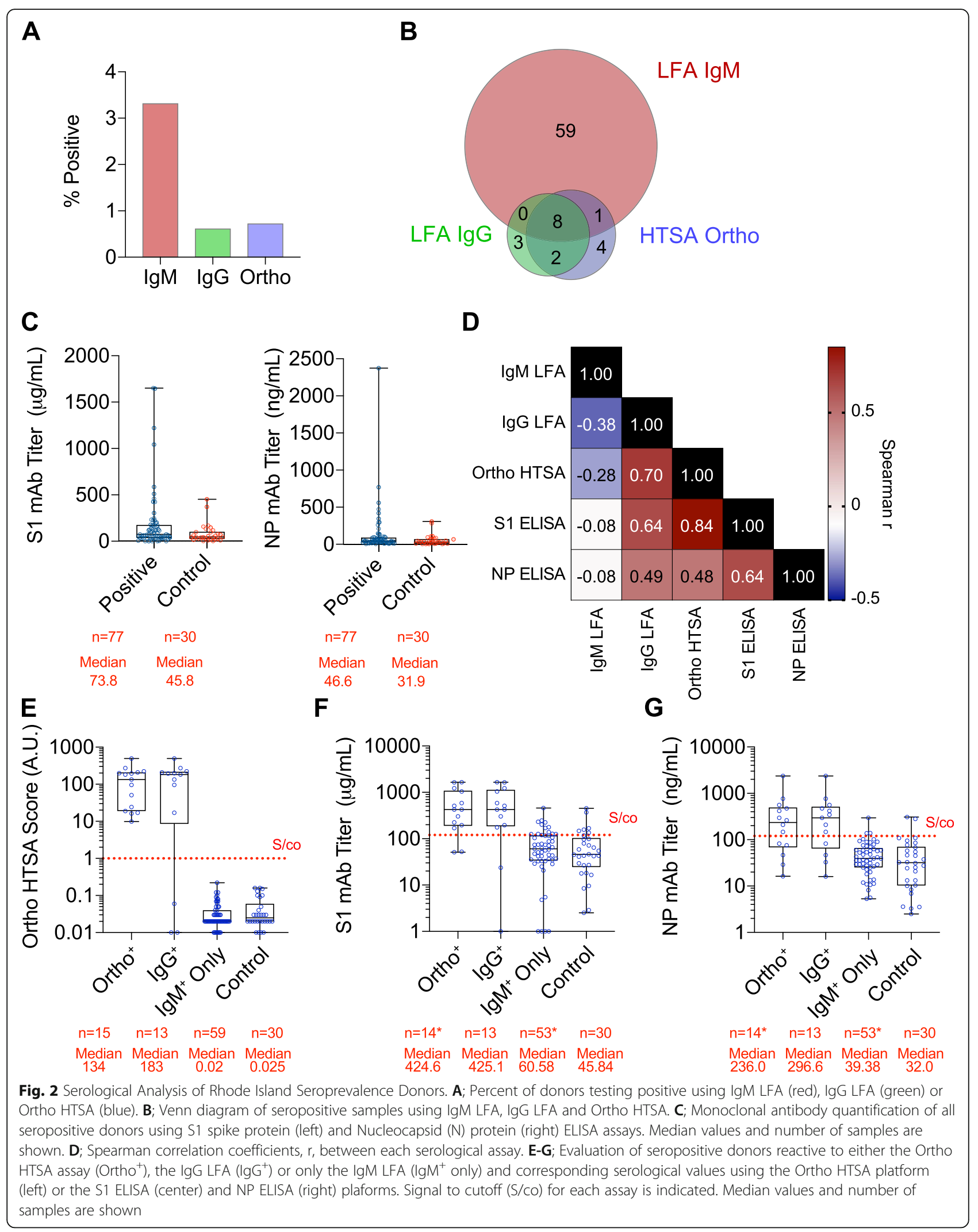


Table 2 Antibody test results and seroprevalence estimates overall and by sex, age and race/ethnicity. Seroprevalence estimates reported in terms of posterior mode and 95\% credible interval, calculated using Bayesian method that adjusts for test sensitivity and specificity. Estimates not reported for categories with 25 test results or fewer. Excludes 11 positive CP/WB Donors and 2 CP/WB donors that tested negative for all three tests. *Posterior mode calculated using a prior distribution having mode equal to the overall seroprevalence for $\lg \mathrm{M}$

\begin{tabular}{|c|c|c|c|c|c|c|c|}
\hline & \multirow[b]{2}{*}{$N$} & \multicolumn{3}{|c|}{ Number Positive } & \multicolumn{3}{|c|}{ Seroprevalence Estimates $(95 \% \mathrm{Cl})$} \\
\hline & & $\lg G$ & $\lg M$ & Ortho & $\lg G$ & $\lg M$ & Ortho \\
\hline Overall & 1996 & 13 & 68 & 14 & $0.6(0.3$ to 1.1$)$ & 2.7 (1.7 to 3.8$)$ & $0.6(0.2$ to 1.1$)$ \\
\hline \multicolumn{8}{|l|}{ Sex } \\
\hline Men & 1057 & 9 & 32 & 11 & 0.8 (0.4 to 1.6$)$ & 2.2 (1.1 to 3.8$)$ & 0.9 (0.3 to 1.8$)$ \\
\hline Women & 939 & 4 & 36 & 3 & $0.3(0.1$ to 1.1$)$ & $3.1(1.8$ to 5.0$)$ & 0.1 (0 to 0.9$)$ \\
\hline \multicolumn{8}{|l|}{ Age } \\
\hline $15-34$ & 348 & 2 & 4 & 5 & $0.6(0.1$ to 2.1$)$ & 0.2 (0 to 2.4 ) & $1.3(0.4$ to 3.4$)$ \\
\hline $35-64$ & 1181 & 5 & 45 & 6 & $0.4(0.1$ to 1.0$)$ & 3.3 (1.9 to 4.8$)$ & 0.4 (0 to 1.0$)$ \\
\hline $65+$ & 467 & 6 & 19 & 3 & 1.2 (0.5 to 2.8$)$ & $3.4(1.6$ to 6.1$)$ & 0.5 (0.1 to 1.8$)$ \\
\hline \multicolumn{8}{|l|}{ Race/Ethnicity } \\
\hline Asian & 5 & 0 & 0 & 0 & & & \\
\hline Black/African American & 11 & 0 & 0 & 0 & & & \\
\hline Hispanic/Latino & 54 & 1 & 0 & 1 & 1.9 (0.4 to 10.2$)$ & $0.5(0$ to 7.7$) *$ & 1.8 (0.3 to 10.3$)$ \\
\hline Native American & 5 & 0 & 0 & 0 & & & \\
\hline White & 1688 & 10 & 57 & 11 & 0.5 (0.2 to 1.1$)$ & 2.7 (1.6 to 3.9) & 0.5 (0.1 to 1.1$)$ \\
\hline Other / Multiple & 24 & 0 & 2 & 0 & & & \\
\hline Unknown / Declined & 209 & 2 & 8 & 2 & $0.9(0.2$ to 3.5$)$ & 3.0 (0.9 to 7.5$)$ & $0.8(0.1$ to 3.5$)$ \\
\hline
\end{tabular}

antibody testing has entered public discourse as an important metric in determining the population seroprevalence of SARS-CoV-2. Ultimately, the application of antibody testing could be clinically informative as to the degree of immunity afforded incurred by recovered patients or to that of future vaccinated individuals.

Table 3 Serology Test Results stratified by reported PCR test result among SARS-CoV-2 Diagnostic PCR Test Respondents

\begin{tabular}{|c|c|c|c|c|}
\hline & & \multicolumn{3}{|c|}{ PCR Result } \\
\hline & & Positive & Negative & Total \\
\hline \multirow[t]{5}{*}{$\lg M$} & Positive & 4 & 4 & 8 \\
\hline & Negative & 9 & 59 & 68 \\
\hline & Total & 13 & 63 & 76 \\
\hline & & \multicolumn{3}{|c|}{ PCR Result } \\
\hline & & Positive & Negative & Total \\
\hline \multirow[t]{5}{*}{$\lg G$} & Positive & 9 & 2 & 11 \\
\hline & Negative & 4 & 61 & 65 \\
\hline & Total & 13 & 63 & 76 \\
\hline & & \multicolumn{3}{|c|}{ PCR Result } \\
\hline & & Positive & Negative & Total \\
\hline \multirow[t]{3}{*}{ Ortho } & Positive & 11 & 2 & 13 \\
\hline & Negative & 2 & 61 & 63 \\
\hline & Total & 13 & 63 & 76 \\
\hline
\end{tabular}

However, we recognize the limitations of the current study include generalizability and limited demographic and other data of the blood donors that may be important. In fact, seroprevalence has been suggested to be higher in specific racial/ethnic communities based on recent studies [14]. Thus, more inclusive and complete seroprevalence studies will need to be performed in the future.

The application of antibody testing could be clinically informative as to the degree of antiviral activity incurred by recovered patients or to that of future vaccinated individuals. Seroprevalence studies have the ability to provide two important metrics: 1) the seroprevalence within a given population and 2) semi-quantification of specific antibodies to SARS-CoV-2 that may correlate with immunity. However, the latter estimation requires that an accurate methodology be adopted at the onset of the study. We recently completed a comprehensive analysis of SARS-CoV-2 serological test characteristics and comparison to antiviral neutralization activity using pseudoviral models [15]. In that investigation, HTSAs were shown to have superior performance characteristics and correlation with neutralizing activity compared to LFAs. It should be noted that the LFAs used in the prior study were different from the LFAs used in this study.

Among Rhode Island blood donors, we found the SD Biosensor IgG LFA and the Ortho HTSA assays both 
reported a $\sim 0.6 \%$ estimated seroprevalence rate. Community seroprevalence estimates were only beginning to be made in May 2020 and questions surrounding testing platform sensitivity and specificity were still being evaluated thus providing no other data to compare our estimation. One study of randomly selected households across Rhode Island in May 2020 found an estimated seroprevalence of $2.1 \%$ (CI: $0.6-4.1 \%$ ) [16]. To surveil the state, the authors performed a statewide crosssectional household survey using HTSA or ELISA serological tests. The discrepancy in seroprevalence estimates between this study and ours can likely be attributed to the skewed donor demographics of blood donors, [17] where minorities are underrepresented. In another study, the first commercial laboratory seroprevalence estimate recorded by the $\mathrm{CDC}$ for the state of Rhode Island was 3.0\% (CI: 1.2-5.5\%) between July 30th and August 5th, 2020 [18]. Therefore, our lower seroprevalence estimate of $\sim 0.6 \%$ during May 2020 would be consistent with the emergence of the second wave of infections which peaked on July 24th, 2020. However, seroprevalence calculations using a relatively limited number of donors coupled with low frequency of detection in the RI population during this period can introduce error into seroprevalence estimate calculations. Furthermore, our study is in agreement with a recent study showing relatively low seroprevalence in many metropolitan areas during this time period [19]. Overall, our study confirms a seroprevalence estimate consistent with other studies performed during this time period and show blood donation centers could be easily deployed to conduct rapid surveillance of regional populations to monitor future waves of COVID-19 and emerging pandemics.

It is tempting to speculate that low rates of seroprevalence is a logical result to the social distancing and mitigation policies that have been adopted by virtually the entire world. However, the SD Biosensor IgM LFA assay had very different performance characteristics, did not correlate with ELISA assays and reported a higher seroprevalence rate. The latter approximation would be similar to the Santa Clara seroprevalence rate reported in April of 2020, which found a seroprevalence rate of 2.5$4.2 \%$ using LFA assays [20]. However, since the IgM LFA assay correlated poorly with the Ortho HTSA assay, which we have previously shown to associate with neutralization activity and antiviral antibody effectiveness to prevent reinfection of cells with pseudovirus, [15] we conclude the SD Biosensor IgM LFA assay may not be informative as to an adaptive immune response to SARS-CoV-2. It should be noted that a concurrent SARS-CoV-2 serology study comparing the SD Biosensor LFAs to another LFA and a chemiluminescent assay concluded that the SD Biosensor IgM LFA had limited clinical utility, while the SD Biosensor IgG LFA performed very well across several distinct population sets and compared to the other assays [21]. However, since the infection status and time course of a potentially infected donor at the time of the blood donation was unknown, and IgM immunoglobin production precedes IgG antibody development, it is possible these donors were either recently infected or experienced a low exposure to SARS-CoV-2 but simply were not producing IgG at donation. Our results caution that seroprevalence rates could be miscalculated by as much as 5 -fold depending whether an IgG or IgM LFA serology test is employed. Thus, prior assessment of serology assay performance should be considered before use in reporting rates of seroprevalence.

LFAs offer the convenience of rapid test results at the point of care and utilization of either whole blood, plasma or serum which makes deployment simple. In this study, we found that the SD Biosensor IgG LFA test provided reliable sensitivity to report seroprevalence. We found in this study that the SD Biosensor IgG LFA test also provided reliable sensitivity to report seroprevalence. However, LFAs do not yield semi-quantitative results which could be used to further understand the immunological range of responses within a study population. Therefore, HTSA platforms are better suited to quantify a wide range of antibody levels in a population while LFAs are suitable for low-cost, rural or studies designed for a limited interpretation of seroprevalence.

\section{Conclusion}

In conclusion, we find the estimated seroprevalence of Rhode Island blood donors to be relatively low, approximately $0.6 \%$ during the month of May, 2020. Thus, we predict undiagnosed and asymptomatic infections are also likely to be low. Considering the possibility that this may be an underestimate of the statewide population, these conclusions draw important findings as it suggests that in the absence of a vaccine, "background" or "herd" immunity to also be low, now four months into the US pandemic, and thus the susceptible population remains at $95 \%$ or greater.

\section{Abbreviations \\ COVID-19: coronavirus disease of 2019; ELISA: enzyme linked immunosorbent assay; EUA: emergency use authorization; FDA: U.S. Food and Drug \\ Administration; HTSA: high throughput serological assay; IgG: immunoglobin gamma; IgM: immunoglobin mu; LFA: lateral flow assay; NP: nucleocapsid protein; NYBC: New York Blood Center; PCR: polymerase chain reaction; S1: S1 domain of spike protein; SARS-CoV-2: severe acute respiratory syndrome; RBD: receptor binding domain of spike protein; RIBC: Rhode Island Blood Center; RIDOH: Rhode Island Department of Health}

\section{Acknowledgements}

We thank Jill Alberigo, Amanda Brites and Kelly Brightman and the laboratory staff from the Rhode Island Blood Center for their help with performing the Ortho Anti-SARS-CoV-2 Total Test collecting donation 
samples and compiling the results of the donor survey. We thank the RIDOH laboratory staff for performing the LFA assays.

\section{Authors' contributions}

The New York Blood Center designed, collected and interpreted the data. DJN and DJ performed ELISAs and prepared Figs. JY and HC prepared figures and compiled data for statistical analysis. JWH performed statistical calculations of seroprevalence estimates and coordinated demographics. MV, EK, and UB performed HTSA and LFA assays. LL designed the in-house ELISAs and supervised data collection, preparation and interpretation. MJS, PAC and $\mathrm{RCH}$ contributed to interpretation and the data. $\mathrm{LL}, \mathrm{JWH}$ and $\mathrm{CDH}$ co-wrote the manuscript. All authors read and approved the submission of the manuscript.

\section{Funding}

Donor collection and performance of the HTSA and LFA serological assays was funded through the Rhode Island Department of Health. Performance of ELISA serological assays and data analysis was data was funded though the New York Blood Center.

\section{Availability of data and materials}

All raw data presented in this manuscript is available on request from the corresponding author.

\section{Declarations}

\section{Ethics approval and consent to participate}

Approval for donation and collection of blood from donors was attained by written consent. All donors were over 16 years of age. Ethical oversight of seroprevalence donation protocols was obtained from the institutional review board of the New York Blood Center.

\section{Consent for publication}

Not applicable.

\section{Competing interests}

The authors declare no competing interests in the generation of this manuscript.

\section{Author details}

'New York Blood Center, Lindsley F. Kimball Research Institute, New York, NY, USA. ${ }^{2}$ Department of Biostatistics, Brown University, Providence, RI, USA. ${ }^{3}$ Rhode Island Department of Health, Providence, RI, USA. ${ }^{4}$ Rhode Island Commerce Corporation, Providence, RI, USA. ${ }^{5}$ Rhode Island State Health Laboratory, Providence, RI, USA.

Received: 16 September 2020 Accepted: 14 July 2021

Published online: 25 August 2021

\section{References}

1. Andersen KG, Rambaut A, Lipkin WI, Holmes EC, Garry RF. The proximal origin of SARS-CoV-2. Nat Med. 2020;26(4):450-2. https://doi.org/10.1038/s41 591-020-0820-9.

2. Wu F, Zhao S, Yu B, Chen YM, Wang W, Song ZG, et al. A new coronavirus associated with human respiratory disease in China. Nature. 2020:579(7798): 265-9. https://doi.org/10.1038/s41586-020-2008-3.

3. Kucharski AJ, Russell TW, Diamond C, Liu Y, Edmunds J, Funk S, et al. Early dynamics of transmission and control of COVID-19: a mathematical modelling study. Lancet Infect Dis. 2020;20(5):553-8. https://doi.org/10.1016/ S1473-3099(20)30144-4.

4. Chan CM, Tse H, Wong SS, Woo PC, Lau SK, Chen L, et al. Examination of seroprevalence of coronavirus HKU1 infection with S protein-based ELISA and neutralization assay against viral spike pseudotyped virus. J Clin Virol. 2009:45(1):54-60. https://doi.org/10.1016/j.jcv.2009.02.011.

5. Lee CY, Lin RTP, Renia L, Ng LFP. Serological approaches for COVID-19: epidemiologic perspective on surveillance and Control. Front Immunol. 2020;11:879. https://doi.org/10.3389/fimmu.2020.00879.

6. Zhong $X$, Yang $H$, Guo ZF, Sin WY, Chen W, Xu J, et al. B-cell responses in patients who have recovered from severe acute respiratory syndrome target a dominant site in the S2 domain of the surface spike glycoprotein. J Virol. 2005;79(6):3401-8. https://doi.org/10.1128/JVI.79.6.3401-3408.2005.
7. Tai W, He L, Zhang X, Pu J, Voronin D, Jiang S, et al. Characterization of the receptor-binding domain (RBD) of 2019 novel coronavirus: implication for development of RBD protein as a viral attachment inhibitor and vaccine. Cell Mol Immunol. 2020;17(6):613-20. https://doi.org/10.1038/ s41423-020-0400-4

8. Chaturvedi R, Naidu R, Sheth S, Chakravarthy K. Efficacy of serology testing in predicting reinfection in patients with SARS-CoV-2. Disaster Med Public Health Prep. 2020:1-7.

9. Deeks JJ, Dinnes J, Takwoingi Y, Davenport C, Spijker R, Taylor-Phillips S, et al. Antibody tests for identification of current and past infection with SARS-CoV-2. Cochrane Database Syst Rev. 2020;6:CD013652.

10. Lachmann A. Correcting under-reported COVID-19 case numbers. medRxiv. 2020.

11. Xu X, Sun J, Nie S, Li H, Kong Y, Liang M, et al. Seroprevalence of immunoglobulin $\mathrm{M}$ and $\mathrm{G}$ antibodies against SARS-CoV-2 in China. Nat Med. 2020.

12. Babicki S, Arndt D, Marcu A, Liang Y, Grant JR, Maciejewski A, et al. Heatmapper: web-enabled heat mapping for all. Nucleic Acids Res. 2016; 44(W1):W147-53. https://doi.org/10.1093/nar/gkw419.

13. Kimberly J Paiva RDG, Philip A Chan, John R. Lonks, Ewa King, Richard C Huard, Diane L Pytel-Parenteau, Ga Hie Nam, Evgeny Yakirevich, Shaolei Lu. Validation and Performance Comparison of Three SARS-CoV-2 Antibody Assays. bioRxiv. 2020.

14. Martinez DA, Hinson JS, Klein EY, Irvin NA, Saheed M, Page KR, et al. SARS CoV-2 positivity rate for Latinos in the Baltimore-Washington. JAMA: DC Region; 2020.

15. Luchsinger LL, Ransegnola B, Jin D, Muecksch F, Weisblum Y, Bao W, et al. Serological Analysis of New York City COVID19 Convalescent Plasma Donors. medRxiv. 2020.

16. Chan PA, King E, Xu Y, Goedel W, Lasher L, Vargas M, et al. Seroprevalence of SARS-CoV-2 antibodies in Rhode Island from a statewide random sample. Am J Public Health. 2021;111(4):700-3. https://doi.org/10.2105/AJPH.2020.3 06115.

17. Shaz BH, James AB, Hillyer KL, Schreiber GB, Hillyer CD. Demographic patterns of blood donors and donations in a large metropolitan area. J Natl Med Assoc. 2011;103(4):351-7. https://doi.org/10.1016/S0027-9684 (15)30316-3.

18. Control CfD. Nationwide Commercial Laboratory Seroprevalence Survey 2021 [Available from: https://covid.cdc.gov/covid-data-tracker/\#national-lab.

19. Havers FP, Reed C, Lim TW, Montgomery JM, Klena JD, Hall AJ, et al. Seroprevalence of Antibodies to SARS-CoV-2 in Six Sites in the United States, March 23-May 3, 2020. medRxiv. 2020.

20. Bendavid E, Mulaney B, Sood N, Shah S, Ling E, Bromley-Dulfano R, et al. COVID-19 antibody Seroprevalence in Santa Clara County, California. 2020

21. Paiva KJ, Grisson RD, Chan PA, Huard RC, Caliendo AM, Lonks JR, et al. Validation and performance comparison of three SARS-CoV-2 antibody assays. J Med Virol. 2020

\section{Publisher's Note}

Springer Nature remains neutral with regard to jurisdictional claims in published maps and institutional affiliations.

Ready to submit your research? Choose BMC and benefit from

- fast, convenient online submission

- thorough peer review by experienced researchers in your field

- rapid publication on acceptance

- support for research data, including large and complex data types

- gold Open Access which fosters wider collaboration and increased citations

- maximum visibility for your research: over $100 \mathrm{M}$ website views per year

At $\mathrm{BMC}$, research is always in progress.

Learn more biomedcentral.com/submissions 